\title{
A Study to Assess the Problem-Solving, Loneliness and Depression among Adolescents in a Selected School of Manipur
}

\author{
Teresa Lamniang', Veena Sharma ${ }^{2}$, Eke Lama Tamang ${ }^{3}$ \\ ${ }^{1} \mathrm{M} . S \mathrm{Sc}$. Nursing $2^{\text {nd }}$ Year Student (Mental Health and Psychiatric Nursing), ${ }^{2}$ Associate Professor, ${ }^{3}$ Nursing Tutor, \\ Rufaida College of Nursing, Jamia Hamdard, New Delhi. \\ DOI: https://doi.org/10.24321/2455.9318.201819
}

\begin{abstract}
Adolescence is the period when physical and emotional problems are experienced, which starts with sexual and psychosocial maturation and ends when the person has developed a sense of identity and become socially productive. This period is characterized with biological, psychological and social developmental changes. In order for an adolescent to grow up to be a healthy adult, he/she needs to have a healthy adolescence. Adolescence is a period of life with specific health and developmental needs and rights. It is also a time to develop knowledge and skills, learn to manage emotions and relationships, and acquire attributes and abilities that will be important for enjoying the adolescent years and assuming adult roles. Keeping this in mind, a cross-sectional study was conducted with objectives to assess the problem-solving abilities among adolescents; to assess the level of loneliness among adolescents; to assess the level of depression among adolescents; and to determine the association of loneliness and depression with problem-solving abilities. The study was conducted among 100 adolescents, studying at Young Pillars College, Churachandpur, Manipur, who were selected through systematic random sampling technique. A structured questionnaire was used for data collection and data was analyzed using descriptive and inferential statistics. The study findings revealed that $75 \%$ adolescents had average problem-solving abilities, $13 \%$ adolescents had good problem-solving abilities and $12 \%$ adolescents had poor problem-solving abilities. $82 \%$ sample subjects had moderate level of loneliness, $9 \%$ had mild loneliness and an equal percentage, i.e., $9 \%$ had severe loneliness. $70 \%$ adolescents had moderate depression, $18 \%$ severe depression and $12 \%$ had mild depression. Therefore, it is necessary to conduct awareness and campaigns on adolescents' mental health issues in the community and educate teachers on adolescents' psychological problems to prevent the occurrence of depression and loneliness among adolescents.
\end{abstract}

Keywords: Problem-solving abilities, Loneliness, Depression, Adolescents

\section{Introduction}

Age is a convenient way to define adolescence. ${ }^{1}$ But it is only one characteristic that delineates this period of development. Age is often more appropriate for assessing and comparing biological changes (e.g. puberty), which are fairly universal, than the social transitions, which vary more with the socio-cultural environment. ${ }^{2}$ Adolescence is one of the most rapid phases of human development. Although the order of many of the changes appears to be universal, their timing and the speed of change vary among and even within individuals. Both the characteristics of an individual (e.g. sex) and external factors (e.g. inadequate nutrition, an abusive environment) influence these changes. ${ }^{3}$

Corresponding Author: Ms. Teresa Lamniang, Rufaida College of Nursing, Jamia Hamdard, New Delhi.

E-mail Id: teresalamniang03@gmail.com

Orcid Id: https://orcid.org/0000-0002-8641-4815

How to cite this article: Lamniang T, Sharma V, Tamang EL. A Study to Assess the Problem-Solving, Loneliness and Depression among Adolescents in a Selected School of Manipur. Int J Nurs Midwif Res 2018; 5(2): 33-37. 
In many ways, adolescent development drives the changes in the disease burden between childhood to adulthood - for example, the increase with age in sexual and reproductive health problems, mental illness and injuries. Changes taking place in the adolescent's environment both affect and are affected by the internal changes of the adolescent. These external influences, which differ among cultures and societies, include social values and norms and the changing roles, responsibilities, relationships and expectations of this period of life.

Globally, 1 out of 10 (10\%) adolescents encounter at least one behavioral problem. Half of lifetime mental disorders begin before the age of 14 years, and $75 \%$ begin by the age of 24 years. ${ }^{4,5}$ Studies completed in Canada and USA have shown that mental health among the adolescent population is a public health issue. ${ }^{6}$ In developing countries, such as Nepal and other South-Asian countries, scenario of mental health and its care system is worse than compared to developed countries. ${ }^{7}$

One of the stages of life where a person feels the loneliest is adolescence. ${ }^{8}$ Because of the changes in the social system like changing social structure and social values, industrialization, urbanization and globalization, feeling of loneliness and depression has become a serious problem among adolescents. Adolescents feel lonely and depressed when they perceive low level of social support, ignored, negatively evaluated, or rejected by their family, peers, and other persons in the society, which has an adverse effect on their psychological development and wellbeing. ${ }^{9}$ Studies report that socioeconomic levels, peer and family relations of adolescents have an effect on their level of loneliness, depression and problem-solving skills. ${ }^{10}$

\section{Objectives}

- To assess the problem-solving abilities in adolescents

- To assess the level of loneliness among adolescents

- To assess the level of depression among adolescents

- To determine the association of loneliness and depression with problem-solving abilities among adolescents

\section{Materials and Methods}

Quantitative research approach was considered to be most appropriate to accomplish the objectives and the research design selected was cross-sectional research design. The sample size comprised of 100 adolescents studying in $11^{\text {th }}$ and $12^{\text {th }}$ class of Young Pillars College, Churachandpur, Manipur. Systematic random sampling technique was adopted considering the feasibility of the study. The tools used for data collection were Standardized UCLA Loneliness Scale to assess the level of loneliness among adolescents,
Standardized Beck's Depression Inventory to assess the level of depression among adolescents and rating scale developed by the investigator to assess the problem-solving abilities among adolescents. Reliability was worked out by using Cronbach's alpha and was found to be 0.85 . Data was analyzed using descriptive and inferential statistics.

\section{Results}

Section I: Description of Demographic Characteristics of the Study Subjects

Table 1.Frequencies and Percentage Distribution Computed for Describing the Demographic Characteristics of Adolescents

\begin{tabular}{|c|c|c|c|}
\hline $\begin{array}{c}\text { S. } \\
\text { No. }\end{array}$ & $\begin{array}{c}\text { Sample } \\
\text { Characteristics }\end{array}$ & Frequency & Percentage \\
\hline 1. & Age (in years) & & \\
\hline & 15 & 17 & 17 \\
\hline & 16 & 22 & 22 \\
\hline & 17 & 34 & 34 \\
\hline & 18 & 27 & 27 \\
\hline 2. & Gender & & 39 \\
\hline & Male & 39 & 61 \\
\hline & Female & 61 & \\
\hline 3. & Educational & & \\
\hline & status & & 76 \\
\hline & $11^{\text {th }}$ class & 24 & \\
\hline & $12^{\text {th }}$ class & 76 & \\
\hline
\end{tabular}

Data in Table 1 presents the frequency and percentage distribution of adolescents by their age, gender and educational status.

Section II: Findings on the Assessment of ProblemSolving Abilities, Loneliness and Depression among Adolescents

Table 2.Mean, Median and Standard Deviation of Problem-Solving, Loneliness and Depression Scores of Adolescents

\begin{tabular}{|c|c|c|c|c|}
\hline Categories & $\begin{array}{c}\text { Range of } \\
\text { Obtained } \\
\text { Scores }\end{array}$ & Mean & Median & $\begin{array}{c}\text { Standard } \\
\text { Devia- } \\
\text { tion }\end{array}$ \\
\hline $\begin{array}{c}\text { Problem- } \\
\text { solving } \\
(0-90)\end{array}$ & $43-56$ & 49.77 & 49 & 6.42 \\
\hline $\begin{array}{c}\text { Loneliness } \\
(0-80)\end{array}$ & $39-52$ & 45.93 & 46 & 6.34 \\
\hline $\begin{array}{c}\text { Depression } \\
(0-63)\end{array}$ & $12-26$ & 19.53 & 19 & 7.23 \\
\hline
\end{tabular}


Table 3.Frequency and Percentage Distribution of Adolescents by the Level of Their Problem-Solving Abilities

\begin{tabular}{|c|c|c|}
\hline Categories & Frequency & Percentage \\
\hline $\begin{array}{c}\text { Poor problem-solving } \\
\text { abilities (0-42) }\end{array}$ & 12 & 12 \\
\hline $\begin{array}{c}\text { Average problem-solving } \\
\text { abilities (43-56) }\end{array}$ & 75 & 75 \\
\hline $\begin{array}{c}\text { Good problem-solving } \\
\text { abilities (57-90) }\end{array}$ & 13 & 13 \\
\hline
\end{tabular}

Data in Table 3 represents the frequency and percentage distribution of adolescents by poor problem-solving abilities, average problem-solving abilities and good problem-solving abilities.

Table 4.Frequency and Percentage Distribution of Adolescents by the Level of Loneliness

\begin{tabular}{|c|c|c|}
\hline Categories & Frequency & Percentage \\
\hline Mild loneliness (0-38) & 9 & 9 \\
\hline $\begin{array}{c}\text { Moderate loneliness } \\
\text { (39-52) }\end{array}$ & 82 & 82 \\
\hline Severe loneliness (53-80) & 9 & 9 \\
\hline
\end{tabular}

Data in the Table 4 shows frequency and percentage distribution of adolescents with moderate level of loneliness, mild level of loneliness and severe level of loneliness.

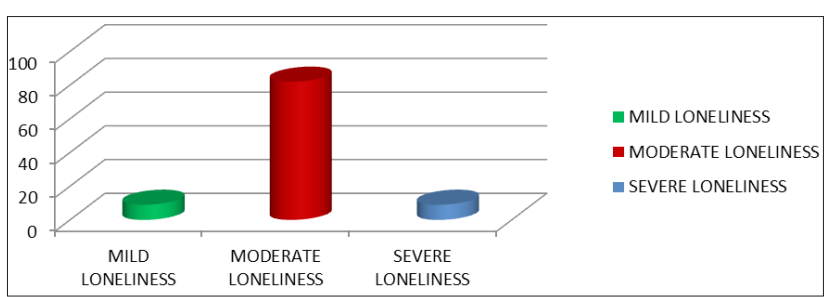

Figure 1.Bar Diagram Depicting the Frequency and Percentage Distribution of the Subjects by Their Level of Loneliness

Table 5.Frequency and Percentage Distribution of the Subjects by the Level of Depression

\begin{tabular}{|c|c|c|}
\hline Categories & Frequency & Percentage \\
\hline Mild depression (0-11) & 12 & 12 \\
\hline $\begin{array}{c}\text { Moderate depression } \\
(12-26)\end{array}$ & 70 & 70 \\
\hline $\begin{array}{c}\text { Severe depression (27- } \\
63)\end{array}$ & 18 & 18 \\
\hline
\end{tabular}

Data in Table 5 reveals frequency and percentage distribution of adolescents with moderate depression, severe depression and mild depression.

Section III: Findings Related to Association between Loneliness and Depression with Problem-Solving Abilities among Adolescents

Table 6.Association between Loneliness with Problem-Solving Abilities among Adolescents

\begin{tabular}{|c|c|c|c|c|c|c|c|}
\hline & & \multicolumn{3}{|c|}{ UCLA Loneliness Scale } & \multirow[t]{2}{*}{ Total } & \multirow[t]{2}{*}{ Fisher's Exact Value } & \multirow[t]{2}{*}{ p-Value } \\
\hline & & Mild & Moderate & Severe & & & \\
\hline \multirow{3}{*}{$\begin{array}{l}\text { Problem-Solving } \\
\text { Abilities }\end{array}$} & Good & 2 & 11 & 0 & 13 & \multirow[t]{4}{*}{5.135} & \multirow[t]{4}{*}{0.176} \\
\hline & Average & 7 & 62 & 6 & 75 & & \\
\hline & Poor & 0 & 9 & 3 & 12 & & \\
\hline \multicolumn{2}{|l|}{ Total } & 9 & 82 & 9 & 100 & & \\
\hline
\end{tabular}

$\mathrm{p}>0.05$, not significant at 0.05 level of significance

Table 7.Association between Depression and Problem-Solving Abilities among Adolescents

\begin{tabular}{|c|c|c|c|c|c|c|c|}
\hline & & \multicolumn{3}{|c|}{ Problem-Solving Abilities } & \multirow[t]{2}{*}{ Total } & \multirow[t]{2}{*}{ Fisher's Exact Value } & \multirow[t]{2}{*}{ p-Value } \\
\hline & & Mild & Moderate & Severe & & & \\
\hline \multirow{3}{*}{$\begin{array}{c}\text { Beck's Depression } \\
\text { Inventory }\end{array}$} & Mild & 3 & 9 & 0 & 12 & \multirow[t]{4}{*}{7.844} & \multirow[t]{4}{*}{0.067} \\
\hline & Moderate & 7 & 56 & 7 & 70 & & \\
\hline & Severe & 3 & 10 & 5 & 18 & & \\
\hline \multicolumn{2}{|l|}{ Total } & 13 & 75 & 12 & 100 & & \\
\hline
\end{tabular}

$p>0.05$, not significant at 0.05 level of significance 
The Fisher's exact value to determine the association between loneliness and problem-solving was 7.844 and the obtained $p$-value was 0.176 . The obtained $p$-value was found to be higher than 0.05 level of significance, which indicates that statistically there is no significant association between loneliness and problem-solving abilities (Table 6). For the determination of association between depression and problem-solving, Fisher's exact value was 7.844 and p-value was 0.067 , which is greater than 0.05 level of significance, indicating no significant association between depression and problem-solving abilities (Table 7).

\section{Discussion}

Depression and loneliness are two characteristic problems of adolescents that is a serious public health concern. It is also assumed that adolescents exhibiting different levels of loneliness and depression would also differ in problemsolving skills Therefore, identifying problem-solving abilities, loneliness and depression levels in adolescents are very important to decide on protective interventions. The present study concluded that a little more than $80 \%$ of the adolescents had moderate level of loneliness; approximately three-fourth of them had moderate level of depression. It also showed that three-fourth of the adolescents had average problem-solving abilities.

The present study revealed that a substantial number of the participating adolescents had different levels of loneliness, where 82 (82\%) sample subjects had moderate level of loneliness, 9 (9\%) sample subjects had mild loneliness and the same number, i.e., 9 (9\%) had severe loneliness. Similarly, a research conducted by Vig and Gill ${ }^{11}$ revealed that a significant level of loneliness existed among adolescents of Chandigarh, where $62 \%$ of adolescents reported loneliness. Contrastingly, in a research conducted by Ronka et al., ${ }^{12}$ it was revealed that most of the adolescents did not report feeling lonely, however, as many as $26.4 \%$ reported being somewhat lonely, and $3.2 \%$ reported being very lonely. Overall, the majority of the adolescents (70.4\%) were not lonely.

The findings from the present study gave us an estimate of the proportion of adolescents experiencing depression where, $70(70 \%)$ adolescents had moderate depression, $18(18 \%)$ had severe depression and $12(12 \%)$ adolescents had mild depression, indicating that more adolescents experience moderate depression. This finding was in line with the study conducted by Goud et al. ${ }^{13}$ which revealed that out of 552 students up to the age of 19 years, 337 (61.1\%) of them were depressed and 215 (38.9\%) of them were normal. Further a study conducted by Bansal et al. ${ }^{14}$ found that out of 125 sample subjects, 102 were not depressed and 23 were depressed, which was in contrast with the present study.

In the present study, it was found that there was no association between depression and problem-solving abilities among adolescents. The findings of this study are in conformity with another study by Weidman et al. ${ }^{15}$ on social problem-solving among adolescents treated for depression. The result showed that there was no significant association between problem-solving abilities and severity of depression.

\section{Conclusion}

The total number of sample for the study was 100 adolescents, out of which three-fourth had average problem-solving abilities and a little more than onefourth adolescents had poor problem-solving abilities. Three-fourth of the adolescents had moderate level of loneliness and depression and the study also revealed that there was no significant association of loneliness and depression with problem solving. The findings of the study have implications for nursing education and nursing administration. In India, the issue of depression, loneliness and poor problem-solving abilities among adolescents is a public health concern. Therefore, nursing education must focus its attention in preparing nurses in such a way that they will be able to deal with adolescents suffering from depression and loneliness. Nurses should be aware of the resources available in the community where such adolescents and their families can seek help when they are unable to cope with their loneliness and depression. Nurse administrators can also provide in-service and continuing education programs for the nurses working in hospitals, schools and communities so that they are involved in promotion of mental health, prevention of mental health problems, and can provide effective nursing interventions related to mental health problems as and when they arise.

\section{Conflict of Interest: None}

\section{References}

1. The state of the world's children 2011: Adolescence an age of opportunity. New York: United Nations Children's Fund 2011.

2. Age limits and adolescence. Paediatrics and Child Health. Canadian Paediatric Society 2003; 8(9): 577.

3. Christie World Health Organization. The World Health Report 2001. Mental Health: New Understanding, New Hope. Geneva: WHO 2001.

4. Kessler C, Berglund P, Demler O et al. Lifetime prevalence and age-of-onset distributions of DSM-IV disorders in the national comorbidity survey replication. Archive of General Psychiatry 2005; 62: 593-602.

5. Jellinek S, Murphy J, Little M et al. Use of the pediatric symptom checklist to screen for psychosocial problems in pediatric primary care: A national feasibility study. Archive of Pediatrics and Adolescent Medicine 1999; 153: 254-60.

6. Polaha J, Dalton W, Allen S. The prevalence of emotional 
and behavior problems in pediatric primary care serving rural children. Journal of Pediatric Psychology 2011; 36: 652-60.

7. Muzammil K, Kishore S, Semwal J. Prevalence of psychosocial problems among adolescents in district Dehradun, Uttarakhand. Indian Journal of Public Health 2009; 53: 18-21.

8. Arumugam, Rajendran, Nagalingam. Mental health problems among adolescents and its psychosocial correlates. Indian Journal of Research 2013; 2: 284-87.

9. Shaheen, Jahan, Shaheen. A study of loneliness in relation to well-being among adolescents. International Journal of Education and Psychological Research 2014; 3(4): 1-2.

10. Segrin C, Nevarez N, Arroyo A et al. Family of origin, environment and adolescent bullying predict young adult loneliness. Journal of Psychology 2012; 146(12): 119-34.
11. Vig, Gill. Assessment of loneliness: A study of Chandigarh adolescents. International Journal of Applied Research 2016; 2(5): 01-04.

12. Rönkä, Rautio, Koiranen et al. Experience of loneliness among adolescent girls and boys. Journal of Youth Studies 2014; 17(2): 183-203.

13. Goud, Ramesh, Kumar. Factors associated with depression among adolescents. Journal of Medical and Health Sciences 2014; 3(4): 73-76.

14. Bansal, Goyal, Srivastava. Study of prevalence of depression in adolescent students of a public school. Indian Psychiatry Journal 2009; 18(1): 43-46.

15. Weidman, Jacobs, Reinecke et al. Behavior Research and Therapy 2010; 48(1): 11-18.

Date of Submission: 2018-05-23 Date of Acceptance: 2018-06-15 